\title{
The Concept of Adequacy in University Libraries
}

\begin{abstract}
The theoretical foundations of the concept of adequacy are examined and shown to be faulty. The term "adequate" cannot meaningfully be applied to a university library collection because the library's contribution to education in the institution is not measurable, yet it is the only basis for determining adequacy. Use of the concept may continue to have some practical benefits but should be clearly distinguished from any theoretical justification.
\end{abstract}

One should not seek for more certainty than the subject matter allows.

\section{-Aristotle}

\section{I}

S IT POSSIBLE to point to a library collection and say with justification that it is either adequate or inadequate? The correct answer to this question should form a fundamental axiom of librarianship. Much of the literature assumes the answer to be yes; however, a logical and linguistic analysis will show that the answer should actually be no, and we shall endeavor to show that attempts to make the measurement are also fundamentally flawed.

Webster's Third International Dictionary defines "adequate" as follows: "equal to, proportionate to, or fully sufficient for a specified or implied requirement; often, narrowly or barely sufficient." Thus it is a quantitative term. Adequacy can be measured. It is also a relative term since it is always measured against some job to be done or some requirement. So, in asking whether a particular library is adequate, we have only to determine what job the library has to do, then measure its collection against that job to see if it has the resources to do it. It appears that nothing could be easier until one tries to do it.

Michael Moran is director of the library, University of Petroleum and Minerals, Dhahran, Saudi Arabia.

\section{THE JOB OF THE UNIVERSITY LIBRARY}

Since the university library is by definition part of a university, its job must be the same as the university's. The job of the university is the higher education of its clientele. The output, the product, of a university is the client who has left the university better educated than before. How much better is a function of the standards of each university and of the particular type of client.

Can this output or product be measured? Certainly the number of graduates can be measured, and it must be agreed that it is possible to measure the number of new facts, ideas, and attitudes absorbed by a client. When a student is given a passing grade, it means that he or she has absorbed at least the minimum of information required. The sources of this additional knowledge in the minds of clients are varied and include classroom teaching, laboratory facilities, work with other students or members of the university, independent research, and, not the least, library facilities.

How much did each of these sources contribute to the educational product, and in what proportion? For example, was the library responsible for 5 percent of the additional knowledge absorbed by the students? At present it would be totally impractical to make this determination, but one thing is certain: all the sources of the 
additional knowledge, including the library's, were adequate. If they were not, the student could not have graduated, research could not have been carried on, contract clients could not have acquired the information they requested. So, by definition, whatever education actually takes place at a university the library is adequate to contribute to it; otherwise, it cannot have taken place. To state the argument another way we could say that the status quo is by definition adequate.

The library should be arguing in its annual request for funds not that it is inadequate to support present educational activity, but that it wishes to support a desired level of future activity. More precisely, the library is seeking funds to increase the quality of education. It is suggesting that students should learn more than they are currently learning, that doctoral candidates should go deeper into their subjects, that researchers should have more data to incorporate into their work. Since quality in education is a key concept, it is well to know exactly how it relates to a library collection.

\section{QUALITY IN EDUCATION}

If a university offers a course in quadratic equations, for example, and that course contributes to a degree program, then the existing library collection must be assumed to be adequate, even though there may not be any books specifically on quadratics. The implicit university policy in this admittedly extreme case is that, even though there are no library books, it feels that the students have learned enough to warrant a degree.

If the library has at least some books or information on quadratics, it may want to acquire others that, though they have the same subject matter, treat the material differently or offer a different approach. Here the library is beginning to contribute to quality, for it is offering clients a chance to proceed up the scale of quality by studying the material from a different point of view on their own in addition to what they have obtained from their professors.

If new contributions previously unavailable at the university are acquired, the library definitely contributes to the educational capability of the university, since the new knowledge extends the limits of the field, changes the theory, increases the applications, etc.

\section{ADEQUACY, POTENTIALITY, AND ACTUALITY}

It is true that the library's actual contribution to education is undefined and immeasurable if defined. Now, taking the extreme situation, assume that no one ever uses the library. Would it then be true that the library is making no contribution whatsoever? An actual contribution, no; but a potential contribution, yes. One purpose of a library is to serve as a repository of knowledge, and by maintaining or acquiring a book, the library has, by that very fact, served this purpose of its being. This is not to say, however, that the library's job is finished when it has acquired a book. The more active the library is in promoting use of its materials, the better the resulting education.

Only the library's actual contribution is the subject matter of adequacy since only when it does make an actual contribution to a client's education is it performing actions subject to measurement against its educational purpose.

Thus far we have attempted to show by linguistic and logical analysis that the term "adequate" cannot be meaningfully applied to a library collection because of the impossibility of measuring the library's educational performance. Nevertheless, we are confronted with many attempts to specify library adequacy. It may be profitable to analyze the more important efforts in order to see whether the theoretical analysis is faulty or whether the attempts are fundamentally flawed by trying to do the impossible. The first involvement with adequacy was in connection with formula budgeting.

\section{FORMULA BUDGETING}

\section{Expenditure per Student and Fixed Percentage}

Early attempts concerned with the concept of adequacy dealt, not with the total size of the collection, but with its annual growth rate. They appeared to have assumed that the status quo was adequate but that certain specified growth rates were 
necessary to maintain adequacy. One way of calculating the desired growth rate was the enrollment method. A certain dollar expenditure per student was defined, and the total was considered to be a minimum desired growth rate. For some years in the 1930s the North Central Association of Colleges and Secondary Schools maintained a standard of $\$ 5.00$ per student. Later the standard became: "Expenditures should be sufficient to cover needed replacements of and additions to the present holdings."1

Does the word "needed" in this context really mean "wanted" (to improve quality) or "adequate" (we cannot do our job without them)? It is conveniently imprecise and is thus, for practical purposes, meaningless.

Related to this method was the standard of a fixed percentage of the university budget for the library budget. In 1930 the United States Office of Education stated that institutions allocating less than 4 percent of their funds for library purposes "should carefully examine ... the adequacy of the book collection." 2

Both approaches were adopted in 1928 by the American Library Association, which recommended a fixed expenditure per student that should not be less than 4 percent of the university budget. ${ }^{3}$

These two approaches are simple examples of formula budgets. A formula budget may be defined as a line item budget "based upon quantitative models evaluating major operating programs and functions and setting numeric guidelines for fund allocations relative to pre-established standards of adequacy and accepted levels of attainment." 4

These two formulas make no statements about the number of volumes. They assume that, if the money is allocated, the "needed" number of volumes will be acquired. But what is the basis for these formulas? ALA's basis was derived simply by a study of 100 colleges and universities. ${ }^{5}$ The formulas carry the assumption that the status quo at the time of the study is normative. What most libraries are getting is what they ought to be getting. This method is well identified by David Kaser as a general method of operation in librarianship in a recent article. Kaser states that "it should be possible to move from careful description of what exists to prescription of what should be." 6

\section{Comparison System}

As we are attempting to show, such a movement is impossible as far as the concept of adequacy is concerned. Since the above systems rely upon what libraries are doing for guidelines as to what they ought to do, they are similar to another system described by McAnally in a 1963 article. ${ }^{7}$ That is the "comparison" system. A library compares itself with other institutions and requests a budget that will give it a desired rank among them. McAnally's paper is fundamentally a description of these various formula budgeting systems rather than a philosophical justification of any one of them. Yet, throughout his paper one theme recurs: none of the then-existing formulas are based, as they should be, upon library needs. But McAnally does not tell us what the needs are for any or all libraries. He asks the rhetorical question, "What is the proper size for a college or a university library, and no subjective judgments, please?" The profession can be grateful to McAnally for at least asking the question.

Now since McAnally's paper is about budgets, which deal with the future acquisitions, we should take the question to mean, What is the ultimate proper size of the collection? How much money does the library need to grow to its ultimate proper size? Implicit in the question is the assumption that once the proper size has been reached the library will grow no more, an assumption McAnally would doubtless have disallowed if given the chance.

\section{Clapp-Jordan}

In 1965, two years after McAnally's article, Clapp and Jordan posed a slightly different question. Instead of asking what was the proper ultimate collection size, they asked what was the proper minimum size. More precisely, when is a library collection adequate? This takes the issue out of the area of budget size and directly into the matter of the collection size. Their thesis is that "it is possible to provide a meaningful quantitative measure of adequacy in library collections." They start by countering Guy Lyle's statement that "the adequacy of the college library's collection cannot be meas- 
ured in quantitative terms." 8 But their formula, in spite of its lip service to quantity, is essentially a statement of quality.

Four of the seven criteria used in their formula (undergraduate library, undergraduate, graduate, and doctoral fields) are based upon the general idea that all books contained in basic bibliographies should be a part of any academic library. The basic collection of 50,750 volumes for the undergraduate library is a kind of generalization or composite taken from catalogs of noted undergraduate libraries. The implication is that the undergraduate library of 50,750 volumes will be composed (by chance? by design?) of these recommended books.

That a certain quantity of books does not assure a certain quality of books seems to be an obvious point, and the question arises as to why Clapp and Jordan ignore it. The answer is that they were really developing a formula that would convince budget officers of the need for money. "It was important that these estimates should carry conviction to the planning, budgeting, and appropriating bodies concerned" and "the results of this attempt .... were found useful for the purpose for which they were designed." They further state: "When standardizing authorities omit or refuse to set standards in quantitative terms, the budgeting and appropriating authorities, who cannot avoid a quantitative basis for their decisions, are compelled to adopt measures which, though perhaps having the virtue of simplicity, may be essentially irrelevant." 9

The Clapp-Jordan formula has the virtue of being ultimately based on bibliographical sources, but it is not a fundamental theoretical contribution to the field. Its real character emerges as a practical approach to dealing with budgeting and budget officers by providing librarians with a pseudoscientific formula for a budget use.

\section{ADEQUACY AND \\ Programming-PlanNING-BUdGETING SYSTEMS}

The Clapp-Jordan formula, because of its scholarly trappings, has gained a measure of acceptance, so much so that some of its principles have been incorporated into program-planning-budgeting (PPB) systems in the states of Washington, Florida, New York, and Texas. ${ }^{10}$ The background and general description of PPB systems are sufficiently covered in the literature and will only be briefly outlined here. ${ }^{11}$

A PPB system includes:

(1) a statement of purpose, including an outline of objectives;

(2) a description of the broad strategy to accomplish the objectives;

(3) a detailed cost of the various options; and

(4) evaluation of the program.

PPB systems can be used by libraries' budgeting agencies to require that libraries define what they need to do their job. Formulas are established for adequacy, and the volumes needed are based on them; but all needs expressed by academic libraries are arbitrary since the library cannot say that it absolutely needs any one book. The library is simply saying that out of the total population of available scholarly materials it has elected to ask for a certain portion. The legitimacy of calling this procedure arbitrary will become apparent immediately if one tries to formulate objectives related to book collecting. For example:

1. "The library will collect 50,000 volumes for the fiscal year." Even in zerobased budgeting, such figures are usually based upon what was acquired last year plus some additional volumes for growth and normally because that was all the money available. If the library had had more money, it would have presumably acquired more books. Yet under PPB systems such extra collecting should not take place because the library did not need any more volumes than the 50,000 . On the other hand, if the 50,000 were not acquired, the library would not cease to do its job.

2. "The library will build a collection of a half million volumes over a five-year period." Is that all the library will ever need to do its job? Certainly not. It is not going to stop acquiring books after it has a half million of them.

These examples show that the program statements of a PPB system may be stated in terms of absolute needs in order to satisfy budgeting agencies, but in reality and in relation to the library's role as an educational agency of the university these needs are arbitrary. The only honest and valid argument that the library can make to the budgeting authority is that it wishes to have additional 
money in some arbitrary amount in order to increase the quality of education it offers the university's clientele.

The library can legitimately argue that its educational potential will immediately decline if the funds are not forthcoming. In addition, its actual contribution will probably decline, although this will happen over a longer period of time. But this decline is not measurable; thus library budget requests do not lend themselves to a PPB system.

\section{ADEQUACY AND STANDARDS}

The budgeting agency may be able to demand that each library define adequacy for itself. That same demand, if made by an agency outside the university system, becomes a standard. Standards may be set by accrediting agencies or by library organizations, such as the American Library Association. One of the latest attempts was formulated by the Association of College and Research Libraries. ${ }^{12}$ The introduction to this document states that the standards "describe a realistic set of conditions which, if fulfilled, will provide an adequate library program in a college." So, at last we have it!

McAnally asked what is the proper size for a library. Clapp-Jordan provided a formula that at least worked in a practical way. And now ACRL is able to crystallize the search into a universal formula. Simply read the standard, and it will be revealed when a library is adequate. But when we read the standard on the collection, it turns out to be nothing more than Clapp-Jordan warmed over. ${ }^{13}$

A "basic collection" of the standard consists of 85,000 volumes. Could they be 85,000 copies of Jack and Jill? The standard itself would allow it. But the commentary on the standard tries to cover the situation:

The goal of college library collection development should be quality rather than quantity. A collection may be said to have quality for its purpose only to the degree that it possesses a portion of the bibliography of each discipline taught, appropriate in quantity both to the level at which each is taught and to the number of students and faculty members who use it. Quality and quantity are separable only in theory: it is possible to have quantity without quality; it is not possible to have quality without quantity defined in relation to the purposes of the institution. No easily applicable criteria have been developed, however, for measuring quality in library collections. ${ }^{14}$

Read this section, keeping in mind that the quality the library is after is the quality of education in the client. In this light the section is a confused mixture of the meaning of the words "quality" and "quantity."

\section{Are Quality and Quantity Separable?}

“' 'Quality' and 'quantity' are separable only in theory." Not true.

This collection of ten books before me has a quantity of ten; no more, no less, and nothing at all need be said about their quality.

If all ten are good quality books on quadratics, then we can say that the whole collection is of excellent quality. If we acquire additional books on quadratic equations, for example, which have different approaches or new material, will the quality be increased? Yes, but if the additions duplicate the scope of the existing collection, the quality will not be increased, only the quantity.

\section{Quality without Quantity?}

"It is not possible to have quality without quantity." We feel that it must be true in some way because many people have the impression that the good libraries are the big libraries. Perhaps we can amplify the statement and thus come to grips with this fundamental question.

The quality of education in a student increases as he or she moves up the scale from rote memory to knowledge of first principles. But not all this knowledge can be contained in one book.

Students of criminal law may know current statute law in their state and may learn it from possibly only one set of books. To get into English common law, Roman criminal law, comparative law, and the philosophy of law itself, however, more books will be required. So the greater the quality of education, the greater the quantity of appropriate books required. But what is the intention of the university with regard to this quality? Does it intend that its students get into the history of Roman criminal law or comparative criminal law? Perhaps it only wants to require of them that they know current statute law and common law. In other words, it is the policy of the decision-making bodies within the univer- 
sity that defines the quality of education in a field. This policy is often not easy to find.

Among the key indicators are formal or informal statements by the administration on university subject emphases, the amount of money allocated to the academic departments, the rank and credentials of the faculty, the number and frequency of course offerings, student enrollments, and the vision the faculty has of its place in the scholarly world. The richer the university is, the more the available money to be spent on each area of a discipline, and the better the quality of education that can be offered as a result of the money available to the library. If a university wants to be excellent in all fields and can afford it, its library will be accordingly better. But indeed, very few universities cover the universe of disciplines with the same intention of excellence for all. Each university is a unique institution with limited goals, limited funds, etc.

The setting of standards by outside agencies, like those in the "Standards for College Libraries," represents an attempt to define a uniformity of purpose and goal on institutions. Such attempts may be ignored by an institution with every justification. If the university wishes to join one of the regional accrediting associations with the view of keeping a check upon the quality of its offered education, it may of course do so. But any abstract formula that presumes to tell a university library how many books it ought to have is foredoomed to failure as a measure of the library's educational role in the university, though not necessarily failure as a financing tool.

\section{Meaning of the ACRL Statement}

So can we now determine what the ACRL statement, that "it is not possible to have quality without quantity," really means and whether it is true or not?

1. Philosophically, the statement is not true in the abstract. Goodness, for example, is a quality, yet it cannot be quantified in any way.

2. It is true in the sense that to have any quality books we must have a certain quantity of books.

3. Taking any subject in the abstract, e.g., apart from any real university situation, a quality collection must be a large one. Assuming easy access and proper bibliographic control, we could say that the best collection of books on a subject is a complete collection of all books ever published on it.

4. Taken in an actual university situation, with clients being given a limited quality of education (e.g., emphasis on practical rather than theoretical knowledge), a relatively small quantity of books could constitute an excellent education for that educational purpose. Now since all libraries are in real situations and since we can presume that the ACRL standards are to be applied to real libraries, then we must say that it is not true that we cannot have quality without quantity. More precisely, we should say that quality does not depend upon any specific number of books.

The ACRL standards attempt to treat library collections in the abstract, as if there were, indeed, a "standard" common to all, But the library's job is to build collections that will educate clients in accordance with the university's intentions, not to build collections for their own sake. The distinction is subtle, but vital, and leads us, reluctantly but with a certain feeling of relief, to deny the validity of standards set by extrauniversity agencies.

\section{ADEQUACY AND GROWTH RATES}

In the past seven years questions of adequacy have concerned themselves more with the adequacy of growth rates, rather than with the current or ultimate size of the collection. This is probably because ClappJordan has cleared the field of discussion on collection size by actually assigning numbers that could not be proved. It will be seen that the same confusion besets these studies that besets those on collection size.

\section{Specifically Identified Needs}

In 1970 Jasper Schad proposed that, when attempting to set up a budget containing allocations by subject, "identified or projected needs are the only valid criteria on which to base budget criteria." $15 \mathrm{He}$ suggested that the library specify every scholarly publication wanted for its own purposes. His system briefly is as follows:

1. Decide at what depth a subject should 
collect (the depth is divided into four levels).

2. Determine the relative importance of the available literature, including monographs, serials, periodicals.

3. Determine the "adequacy of existing holdings."

4. Select specific titles and assign costs to them, including in-print and out-of-print books. The budget is then split into a current imprints section plus a supplementary section for everything else.

Having set up what appears to be a perfectly logical system, Schad states that "while it is easy in theory to define such an approach, it is hard to do in practice." He does not analyze why it is hard, although he hints at the reason by admitting that "complete objectivity in evaluating books and book needs is illusory." We must agree with this self-criticism. And what is illusory about the objectivity is the idea that the adequacy of existing holdings can be determined and that the library can state that it absolutely needs this or that book or it cannot do its job of educating clients. Schad's system at least has the virtue of internal consistency in that proper collection building requires that new acquisitions be related to existing holdings.

\section{Needs Established by Reviews}

Also in 1970 Massman and Patterson proposed that new books receiving favorable book reviews form the basis of minimum budget standards. ${ }^{17}$ The total of these reviews forms the budget for current acquisitions. The assumption here is that if the publication is a good one and the subject is taught by the institution then it is to be presumed that the institution needs the publication. Therefore, to remain adequate the institution needs the book.

Here again we see the all-encompassing idealized university, where all academic departments have the same educational intention, the same levels of quality, the same quality of faculty, the same quality of students. Massman and Patterson are doing what the standards attempt to do: tell each university what it needs on the basis of an idealized picture. It should be noted that Massman has retreated from the idea that a meaningful budget for current acquisitions can be developed on the basis of reviews and has fled into the world of fantasy by proposing that ALA select our books for us. ${ }^{18}$

\section{The Indefiniteness of Needs}

In 1972 Redmond, Sinclair, and Brown published a very interesting study on university libraries and university research. ${ }^{19}$ One of their axioms is that demand for library materials is potentially limitless. This idea seems to mean that any book ever published might be of some use to someone coming in to use the library. This is the old idea that a library could collect everything with some profit. Even the theoretical acceptance of this axiom is in contrast to the more recent idea that there is such a thing as adequacy and that adequacy does not require all the books published.

Adequacy advocates could argue that if it can be shown that a certain number of books is adequate and if that number is less than all the books ever published or to be published then demand is not potentially limitless. The Redmond-Sinclair-Brown axiom is really the correct one, however, because it does not attempt to say that some books are "needed" and some are not. For any book, someone could establish a need, yet the lack of no one book will cause the library to cease carrying out its educational goal within the university.

The authors show that an attempt must be made to limit the demand, not by setting up arbitrary standards, but by matching the resources of the library with the actual research interests of the faculty. The importance of this idea is that it is treating the actual situation in a university, rather than addressing itself to a model. If the recommendations of this article were to be put into practice, one would still find the library administration arguing with faculty members over what is needed to support their research. The result would be an actual money allocation, which would be a statement, not of what is needed, but of what is possible under the circumstances. Growth rates for Redmond, Sinclair, and Brown are strictly limited, as far as research is concerned, by the actual situation in the library, the money available, and the desires of the faculty. 


\section{Current Acquisitions}

The most recent development of the idea of adequacy of growth rates has been that of Voigt. Reviewing attempts to determine the ultimate size for a collection, he made this statement: "Over an extensive time period, size has always been a meaningless term, for as long as scholarship continues and results in printed material or other physical substitutes for print, such material will be added to research libraries."20

Coming from one of Voigt's stature in the profession this is a very significant statement. It is true that his intention in writing this paper was to emphasize the primary importance of growth rates rather than to offer a critique of ultimate collection size.

But Voigt continued with this further statement: "When a reasonable start has been made in building an adequate research collection, first consideration must be given to maintaining a satisfactory acquisition rate." 21 This statement further propagates the confusion over the issue of adequacy. It could be given one of two interpretations:

1. The collection is given. We do not have to say whether it is adequate or not. Let us just say that the library has been in existence for a period of time and the collection has been built by competent people and so forth, so that we can assume adequacy. The use of the words "reasonable start" gives a sense of security. The main thing is to keep collection building going.

2. The existing collection is not adequate since only a start has been made in developing it. But we are not going to worry about that since over a period of time the most important thing is what is added to the collection, not what it was before.

These interpretations attempt to serve as a theoretical justification for splitting off the current acquisitions budget from the retrospective acquisitions. The idea is to get all the current material so that lacunae will not develop from this point on. This will be one budget. Then we can also go back and pick up lacunae from former years, using specially allocated funds to do so. But this brings us right back to the original question: When will that back collection be adequate?

By leaving the question of retrospective purchases out of consideration, Voigt ig- nored the issues involved in calculating adequacy of the total collection and addressed himself only to the adequacy of acquisitions of current imprints. However, he failed to justify splitting off a budget for current imprint acquisitions from the one for retrospective acquisitions.

Voigt actually simply transfered the locus of the problem of adequacy from the collection as a whole to the current imprints collection acquired within any particular fiscal year. His question is, What acquisition rate is adequate for academic and research requirements? To answer the question, he developed a model based on seven factors. The first of these is a "base" rate of 40,000 volumes. Now, as with all these models, the immediate question is, Why 40,000 ? According to Voigt, this figure was not established simply by adding the basic needs for all subjects together since many of them overlap, but rather is based on "cumulative experience." The presumption is, although Voigt does not use the word, that this will form an "adequate" base acquisitions rate. Would 30,000 volumes not be enough? Would 50,000 be too many? In Basic Principle No. 2, Voigt gave the real reason for these figures. "The level . . . supplies those materials without which quality master's and advanced graduate programs could not exist." 22 In other words, we return again to the question of quality in education.

But it is not Voigt or anyone else who can tell the university what the quality of its education is to be. The decision is made by the decision-making bodies within the university. This is the fundamental flaw of all library standards and models: they attempt to impose a uniform quality upon the educational output of all universities where in reality no such uniformity exists or can exist.

We have examined the various attempts at specifying adequacy but have found nothing in them that causes us to alter the theoretical conclusion outlined at the beginning of this paper: that adequacy is not a concept that can be meaningfully applied to a university library collection.

\section{ALTERNATIVES}

Statements of adequacy may be useful on a practical level, even though not valid theoretically. A university library with a collec- 
tion well below a standard may use it to obtain additional allocations. Those with collections well over the levels defined as adequate may properly keep quiet about it when talking to their budget officers.

If, in spite of our denial of the validity of the concept of adequacy, budget officers continue to demand volume counts, it is certainly permissible to give them. Such figures are very consoling to budget officers as they feel that they have some basis for giving the library all that money, even though they have not felt compelled to examine the rationale behind the figures.

If we cannot justify budget requests on the basis of adequacy, what are we to do? I believe it is the responsibility of the collection development librarians to make a mature professional effort to determine the actual quality of education offered at their institutions and to tailor the collection development to suit that quality. If the library is not given the resources it would like, it should be taken as the educational decision of the university.

The comparison method is probably still the best method of approaching budget officers. We have every right to make the case to budget officers that we would like to achieve higher quality in our own university libraries by moving closer to the collection size of the libraries of known excellent quality. This is probably the most honest statement we can make.

It builds up our sense of professionalism to quote formulas and to have standards that are measurable, but the true professionals are those who know the basic principles of their disciplines and who are willing to work within them, and who do not seek more certainty than is allowed. If we are not able to convey this idea to the public that supports us, we are simply thereby admitting that we do not know how to do our job of educating.

\section{REFERENCES}

1. Harvie Branscomb, Teaching with Books (Hamden, Conn: Shoe String Press, 1974, Repr. of the 1940 ed.), p. 210.

2. Quoted in Branscomb, Teaching with Books, p.211.

3. Quoted in Branscomb, Teaching with Books, p.211.

4. Kenneth S. Allen, "Current and Emerging Budgeting Techniques in Academic Libraries, Including a Critique of the Model Budget Program of the State of Washington" (Unpublished typescript, 1972), p.4.

5. Branscomb, Teaching with Books, p.211.

6. David Kaser, "A Century of Academic Librarianship, as Reflected in Its Literature," College b Research Libraries 37:117 (March 1976.) Italics in original.

7. Arthur M. McAnally, "Budgets by Formula," Library Quarterly 33:159-71 (April 1963).

8. Guy R. Lyle, The Administration of the College Library (3d ed.; New York: Wilson, 1961), p.330.

9. Verner W. Clapp and Robert T. Jordan, "Quantitative Criteria for Adequacy of Academic Library Collections," College $b$ Research Libraries 33:373 (Sept. 1965).

10. Allen, "Current and Emerging Budgeting Techniques," p. 4.

11. A good general description as applied to libraries is Harold R. Jenkins, "The ABCs of
PPB," Library Journal 96:3089-93 (Oct. 1971).

12. "Standards for College Libraries," College d Research Libraries News 9:278-301 (Oct. 1975).

13. Standard 2.1.1. "Standards for College Libraries," p. 278.

14. Ibid., p. 290.

15. Jasper G. Schad, "Allocating Book Funds: Control of Planning," College d Research Libraries 31:155-59 (May 1970).

16. Ibid., p. 159 .

17. Virgil F. Massman and Kelley Patterson, "A Minimum Budget for Current Acquisitions," College \& Research Libraries 31:83-88 (March 1970).

18. Virgil F. Massman and David R. Olson, "Book Selection: A National Plan for Small Academic Libraries," College \& Research Libraries, 32:271-79 (July 1971).

19. Donald A. Redmond, Michael P. Sinclair, and Elinore Brown, "University Libraries and University Research," College $\&$ Research Libraries 33:447-53 (Nov. 1972).

20. Melvin J. Voigt, "Acquisition Rates in University Libraries," College \& Research $\mathrm{Li}$ braries $36: 264$ (July 1975).

21. Ibid., p. 264.

22. Ibid., p. 266. 